\title{
Preparation of Fly Ash Granules with Respect to Mine Filling
}

\author{
Anamika Masoom, Manish Kumar Jain, and Rayasam Venugopal
}

\begin{abstract}
The present study has focused on the bulk utilisation of fly ash at the mining sites for the purpose of back filling by agglomerating the fly ash fines with the help of suitable binder and water. The use of fly ash as a stowing material has been justified by studying the physical, morphological, chemical and geotechnical properties of the fly ash. Rheology of the fly ash slurry has also been studied which deduced consumption of lot of water during its hydraulic transportation. To overcome the drawbacks, spherical granules have been prepared with the help of a Disc Pelletizer in which the requisite amount of water and binder (lime) have been finalised as $35 \%$ and $30 \%$ by weight of the fly ash. Granules have been obtained at various combinations of disc speed $(35,40$ 45 RPM) and disc inclination $\left(42^{\circ}, 45^{\circ}, 48^{\circ}\right)$ and each combination has been analysed for Green Compressive Strength and Drop Number. It has been concluded that the granules prepared at $45 \mathrm{RPM}$ and $45^{\circ}$ inclination gave the best results. This utilisation of fly ash granules for the purpose of mine back filling could effectively replace sand which has been conventionally used by providing better flowability, compaction and permeability.
\end{abstract}

Index Terms-Agglomeration, binder, drop number, green compressive strength, pelletisation, rheology.

\section{INTRODUCTION}

After the mining activity is completed, it is a very common practice followed to fill up the mining site with stowing materials, such as sand, fly ash, mine tailings, etc. The stowing materials which are being widely used from a very long time for the particular purpose are sand and mill tailings [1].

Sand obtained from the river beds possess apt physical properties to justify its use in mine back filling. Due to increase in mining activity, more quantity of sand is required which in turn is increasing the pressure on the river beds. Due to the massive utilisation of sand in the construction sector and its non-replenishment in the rivers because of the construction of dams on the upstream side, the availability of the sand has become limited or scarce. Thus, the use of alternate stowing materials are being emphasized [2].

Filling up of mining sites with fly ash has become a customary practice worldwide. Fly ash is the byproduct obtained from the coal based thermal power plants. According to the Central Electricity Authority (CEA) of India, 169.25 million tonnes of fly ash was produced in the financial year 2016-2017 [3]. This implies that fly ash

Manuscript received November 4, 2018; revised February 12, 2019.

Anamika Masoom and Manish Kumar Jain are with the Department of Environmental Science and Engineering, IIT (ISM), Dhanbad (e-mail: manishjkm@gmail.com, manish@iitism.ac.in).

Rayasam Venugopal is with the Department of Fuel \& Mineral Engineering, IIT (ISM), Dhanbad. generation is abundant in our country and its utilisation in the field of mine back filling could be fostered. Moreover, the power plants are located mostly in the vicinity of coal mining area and thus transportation of fly ash would be easy as compared to sand from the river beds which are 50-80 kilometers away from the mining sites [4]. The physical properties such as bulk density, porosity, permeability, specific gravity, Atterberg's limits, water holding capacity and particle size distribution suggest that fly ash is suitable as a stowing material [5]. The use of fly ash could replace sand with increased benefits.

Fly ash is basic in nature having $\mathrm{pH}$ value ranging from 7-10. The filling up of mine sites and mine pits with fly ash has proved to be beneficial where Acid Mine Drainage is prominent [5]. The basic property of fly ash neutralizes the acidic waters present at the mine site and further restricts the generation of AMD by cutting off the contact between pyrites and oxygen. The filling up of fly ash with proper compaction also reduces the risk of subsidence at the mining sites [6]. Fly ash has high water holding capacity and absolutely no plasticity.

Since the fly ash is very fine in nature, during its handling, storage and transportation, huge amount of dust is produced in the surroundings which could lead to irritation of eyes, skin, nose, throat and respiratory tract [7]. Their storage also requires a huge amount of space. Previously, the fly ash was dumped on to the barren lands which could lead to soil degradation and could possibly be a threat to both humans and environment. Besides, fly ash when comes in contact with the surface water or rain water for a long time, it starts leaching heavy metals along with the water. This has potential of further contaminating our ground water reserves with the heavy metals. And, this leaching of heavy metals is more prominent in acidic medium [8]. Further studies have revealed that when fly ash is hydraulically transported to the fill site, they tend to clog the pipes as they try to settle down [9]. This increases the pressure on the pumps which are being used for the particular purpose and also consumes a lot of water.

Due to the above mentioned reasons, the use of fly ash composites are gaining acquaintance. Previous studies have engrossed the mixing of fly ash with lime, gypsum, cement, powdered coal, etc. to overcome the potential problems associated with the use of fly ash alone [1], [10]. In the present study, the fly ash fines have been agglomerated with water and lime as a binder. Water alone cannot bind the fly ash particles since they are hygroscopic in nature, thus, lime has been used [11]. Small spherical granules have been prepared in a rotating Disc Pelletizer by varying the disc parameters such as disc speed and its inclination with the horizontal [12]. The granules possessed sufficient strength to 
be handled, transported and stored. This was ensured by studying the help of granule properties such as Drop number and Green Compressive Strength of the green granules.

The concept of granulation of fly ash could help the industries as well as the thermal power plants to store and use the granules when required. The granules could be stock pilled and this would require less space as compared to that with the fine, powdery fly ash. Also, their hydraulic transportation would improve in the form of spherical granules. Due to the spherical particles obtained, the packing of the granules would be better and permeability will reduce. And, because of the presence of lime along with the fly ash, the leaching of the heavy metals would reduce. The solution of lime with water is considered basic in nature. Thus, it would restrict the leaching of heavy metals from the fly ash into the ground water reserves.

\section{MATERIALS AND MethoD}

\section{A. Sample Collection}

The fly ash sample was collected from Chandrapura Thermal Power Plant located in Bokaro district in Jharkhand. The power plant is operated by the Damodar Valley Corporation. It has 5 units with total installed capacity of 920MW. The primary fuel used in the plant is bituminous coal. Fly ash was collected directly from the bottom of the hoppers which are connected to the Electrostatic Precipitators.

\section{B. Characterisation of Fly Ash}

\section{1) Physical parameters}

The colour and appearance of the fly ash sample collected was noted down by observation. The $\mathrm{pH}$ and electrical conductivity were determined using Multi- Parameter PCS Tester 35 according to the standards HANNA HI $5521 \mathrm{HI}$ 5522 .

\section{Morphology and Chemical Composition}

The morphology of the collected fly ash sample and the elemental composition was studied using micrographs obtained from a SEM-EDX ZEISS (SUPRA 55) model Scanning electron Microscope (SEM). The elemental composition of the fly ash sample was also obtained from it. Since, the fly ash sample was non-conducting in nature, thin gold coating was done on the fly ash before the analysis. The chemical composition of the fly ash was determined using a ZSX PRIMUS II X-Ray Fluorescence (XRF) analyzer.

\section{1) Geotechnical properties}

Various geotechnical parameters of the fly ash sample were studied according to their standard procedures. Bulk density of the fly ash sample was determined by calculating mass per unit volume. The specific gravity of the fly ash sample was determined using the density bottles according to IS: 2720 (part III). The porosity of the fly ash sample was calculated by taking a known volume of fly ash sample in a measuring cylinder and distilled water in a burette. The water was gradually added to the known volume to fly ash taken till the water just appears at the top surface of fly ash. This volume of water added gave the volume of voids present in the known volume of sample. Thus, porosity was calculated using the given formula:

$$
\text { Porosity }=\frac{\text { Volume of voids present }}{\text { Volume of solids }} \times 100 \quad \text { (eqn 1) }
$$

The particle size distribution was estimated by sieve analysis according to the ASTM D 422. The sieves for fine sieve analysis were arranged in the order $-4.75 \mathrm{~mm}, 2.18 \mathrm{~mm}$, $1.18 \mathrm{~mm}, 600 \mu \mathrm{m}, 400 \mu \mathrm{m}, 212 \mu \mathrm{m}, 150 \mu \mathrm{m}$ and $75 \mu \mathrm{m} .$. The compaction properties of the fly ash were studied using the standard Proctor Test according to IS: 2720 (Part VII). The dry densities were obtained for different percentages of addition of water at $10 \%, 15 \%, 20 \%, 25 \%$, and $30 \%$ by weight of fly ash. Using these values Compaction Curve was obtained from where the Maximum Dry Density (MDD) and the corresponding Optimum Moisture Content (OMC) was found. The liquid limit of the fly ash was obtained with the help of Casagrande's apparatus according to IS: 2720 (Part V). The plastic limit of the fly ash was performed according to the IS: 2720 (Part V). The coefficient of hydraulic conductivity of the fly ash sample was determined using the falling head apparatus according to IS: 2720 (Part XVII).

The coefficient of hydraulic conductivity was calculated using the formula:

$$
\mathrm{K}=\frac{a \times L}{A x t} \ln \frac{h 1}{h 2}(\text { eqn 2) }
$$

where, $a=$ area of the stand pipe

$L=$ length of fly ash specimen

$A=$ area of the mould

$t=$ time interval in sec

$h_{1}$ and $h_{2}$ are the initial and final heads as observed from the stand pipe

Water Holding Capacity of the fly ash sample was calculated using the keen box method according to IS: 14765 (2000).

\section{Rheological Properties}

The rheological properties of the fly ash was studied at varying solid concentration using an Anton Paar Rheometer (Rheolab QC) and the measuring system CC27 of the Anton Paar Rheometer. $100 \mathrm{ml}$ slurry was prepared by mixing the fly ash at varying concentrations such as $10 \%, 20 \%, 30 \% 40 \%$ and $50 \%$ by weight of fly ash with distilled water. After preparation, the slurry was covered with aluminium foil to avoid evaporation. Before conducting the test, the sample was allowed to hydrate for one hour. The slurry sample was transferred into the cup and was stirred with a glass rod. The bob was then lowered into the cup. The tests were conducted at a shear rate varying from 0 to $1000 \mathrm{~s}^{-1}$ at the constant temperature $40^{\circ} \mathrm{C}$. The flow curves, called as Rheograms were obtained from the software 'Rheoplus'. Similar procedure was followed for other concentrations of fly ash. Plots of varying shear rate and shear stress were plotted.

\section{E. Granulation of Fly Ash}

The fly ash fines were agglomerated with the help of suitable binder and water in a fixed proportion. This process of agglomeration took place in a rotating Disc Pelletizer have disc diameter of $40 \mathrm{~cm}$ fixed at an inclination with the horizontal which can be adjusted as per requirement. It 
contains two scrap blades fixed at a distance to remove the material from sticking at the periphery of the disc. About 600 grams of oven dried sample of fly ash was taken in a tray. Various dummy experiments were performed to determine the requisite amount of binder, i.e., lime and water at which the prepared granules possessed sufficient strength to be handled, transported and stored. The quantity of lime which was found appropriate was $30 \%$ by weight of fly ash i.e., 180 grams of fine powdered lime was mixed thoroughly with the fly ash. About $10 \%$ of the water i.e., $60 \mathrm{ml}$ was premixed with the lime and fly ash mixture. The mixture was left for 30 minutes so that the moisture gets evenly distributed. The mixture was then transferred on to the disc where a burette was fixed at an inclination for further addition of water. The disc parameters such as disc rotation and disc inclination was fixed at $40 \mathrm{RPM}$ and $42^{\circ}$ respectively. Continuous drop wise water addition of about $25 \%$ i.e., $150 \mathrm{ml}$ was provided. After 20-25 minutes, prepared granules were obtained. The prepared granules were procured and their Green Compressive Strength were found out. The drop number was also determined by dropping 15-20 granules from a height of $40 \mathrm{~cm}$ onto the floor. The drop number is given by the average number of drops before the granule gets distorted or breaks apart. Experiments were performed by varying the disc parameters and respective drop numbers and GCS were studied. The prepared granules were air dried.

\section{RESUlts AND Discussion}

\section{A. Characterisation of Fly Ash}

\section{1) Physical parameters}

The $\mathrm{pH}$ of the fly ash sample was found to be 7.83 and the electrical conductivity was found to be $0.57 \mu \mathrm{S} / \mathrm{cm}$. The colour the fly ash obtained was grey and was fine powdery in appearance. The $\mathrm{pH}$ of the fly ash was found to be alkaline. This inherent alkalinity could aid the mine void filling process where acidic water or Acid Mine Drainage issues are handled [5].

TABLE I: ELEMENTAL ANALYSIS

\begin{tabular}{|c|c|c|}
\hline Element & Weight \% & Atomic\% \\
\hline $\mathrm{C} \mathrm{K}$ & 20.34 & 30.09 \\
\hline $\mathrm{OK}$ & 43.40 & 48.19 \\
\hline $\mathrm{Al} \mathrm{K}$ & 11.48 & 7.56 \\
\hline Si K & 19.49 & 12.33 \\
\hline K K & 0.75 & 0.34 \\
\hline Ti K & 0.90 & 0.34 \\
\hline $\mathrm{Fe} \mathrm{K}$ & 3.64 & 1.16 \\
\hline Totals & 100.00 & \\
\hline
\end{tabular}

\section{2) Morphology and chemical composition}

The magnified images of the fly ash sample were obtained from a Scanning Electron Microscope at 1.00X and 8.00X magnifications as shown in Fig. 1.

From the micrographs, it can be seen that the fly ash particles are found to be smooth and spherical which can be attributed to the presence of silica and mullite. The elemental analysis was also obtained and is shown in Fig. 2 and listed in Table I. The chemical composition analysis was obtained through an X-Ray Fluorescence Analyzer (XRF) which is tabulated in Table II. From the obtained results we found that, $\mathrm{SiO}_{2}$ was present in abundant amount in the fly ash which describes that fly ash possesses sufficient strength to be used as a fill material.

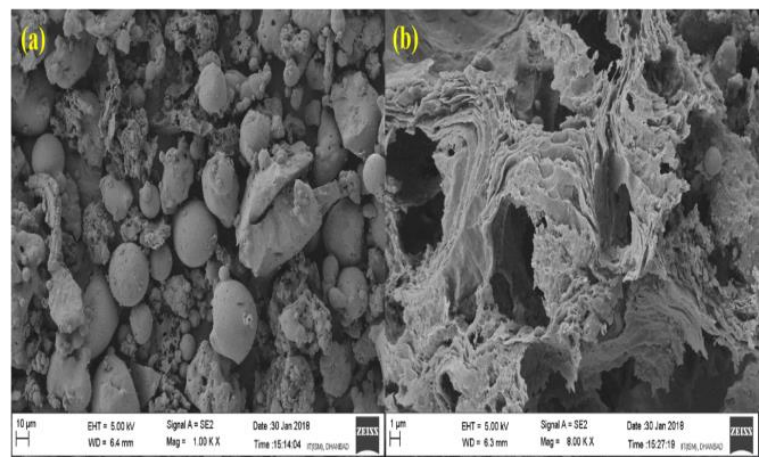

Fig. 1. Micrographs from SEM.

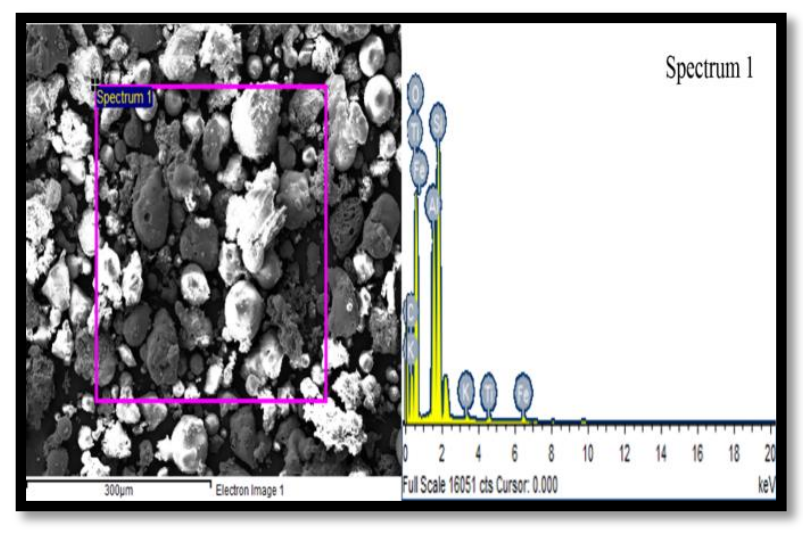

Fig. 2. Elemental analysis

The mass percent concentration of $\mathrm{Al}_{2} \mathrm{O}_{3}, \mathrm{Fe}_{2} \mathrm{O}_{3}$ and $\mathrm{SiO}_{2}$ were found to be more than $75 \%$ of the total mass. This concludes that the sample of fly ash corresponds to class F fly ash as per ASTM C-618 specifications [9]. The presence of $\mathrm{CaO}$ is very less which concludes that the fly ash could not be used as a binding material like cement. But, its utilization by blending with lime could give better strength results due to the presence of $\mathrm{Al}_{2} \mathrm{O}_{3}, \mathrm{Fe}_{2} \mathrm{O}_{3}$ and $\mathrm{SiO}_{2}$ in sufficient amount [13].

TABLE II: CHEMICAL COMPOSITION OF THE CTPS FLY ASH

\begin{tabular}{|c|l|l|}
\hline SI.No. & COMPOUND & CONCENTRATION (in \%) \\
\hline 1. & $\mathrm{Al}_{2} \mathrm{O}_{3}$ & 25.519 \\
\hline 2. & $\mathrm{CaO}$ & 0.392 \\
\hline 3. & $\mathrm{Fe}_{2} \mathrm{O}_{3}$ & 4.468 \\
\hline 4. & $\mathrm{~K}_{2} \mathrm{O}$ & 1.027 \\
\hline 5. & $\mathrm{MgO}$ & 0.453 \\
\hline 6. & $\mathrm{Na}_{2} \mathrm{O}$ & 0.00 \\
\hline 7. & $\mathrm{P}_{2} \mathrm{O}_{5}$ & 0.302 \\
\hline 8. & $\mathrm{SiO}_{2}$ & 50.874 \\
\hline 9. & $\mathrm{TiO}_{2}$ & 1.881 \\
\hline 10. & $\mathrm{NiO}^{2 O}$ & 0.006 \\
\hline 11. & $\mathrm{MnO}$ & 0.048 \\
\hline
\end{tabular}

\section{3) Geotechnical properties}

Various geotechnical properties of the fly ash were determined so that its use as a stowing material could be fostered. The bulk density of the fly ash sample was found to be $0.85 \mathrm{~g} / \mathrm{cc}$ and the specific gravity was found to be 1.70 . 
This suggests that fly ash is a light weight material and could be used for the purpose of mine back filling [14]. But, also during its transportation or handling, huge amount of dust would be produced, reason being the very fine particles of fly ash getting suspended in the environment nearby [15]. The porosity and coefficient of hydraulic conductivity of the fly ash sample was found to be $57 \%$ and $1.566 \times 10^{-4} \mathrm{~cm} / \mathrm{s}$ respectively. Due to the very fine particles present in the fly ash, the permeability is found to be less than that of coarser materials. This is attributed to the silty sandy texture of the fly ash[14], [16]. The fine sieve analysis was performed to find the average size of the fly ash particles or the $\mathrm{d}_{50}$ size as $220 \mu \mathrm{m}$. This was found out from the graph having percentage passing on the $\mathrm{y}$-axis and sieve size on the $\mathrm{x}$-axis as shown in Fig. 3.

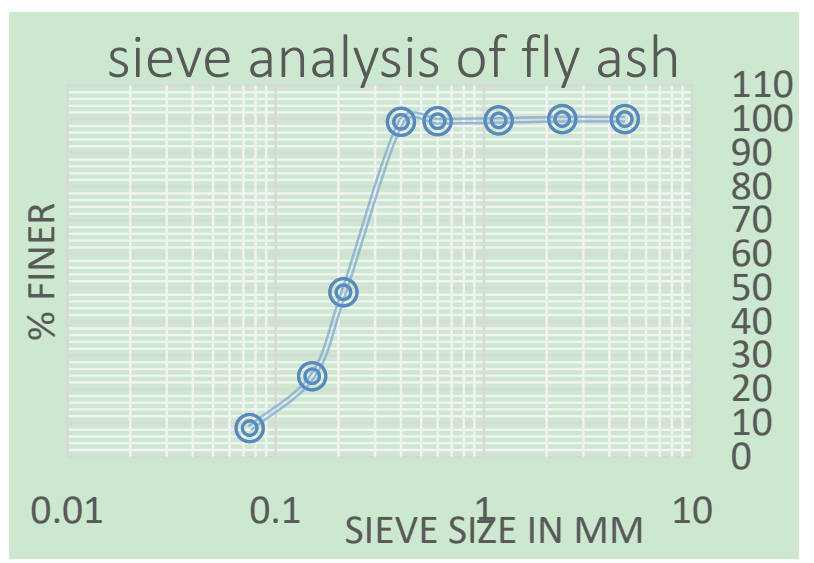

Fig. 3. Sieve analysis graph of fly ash.

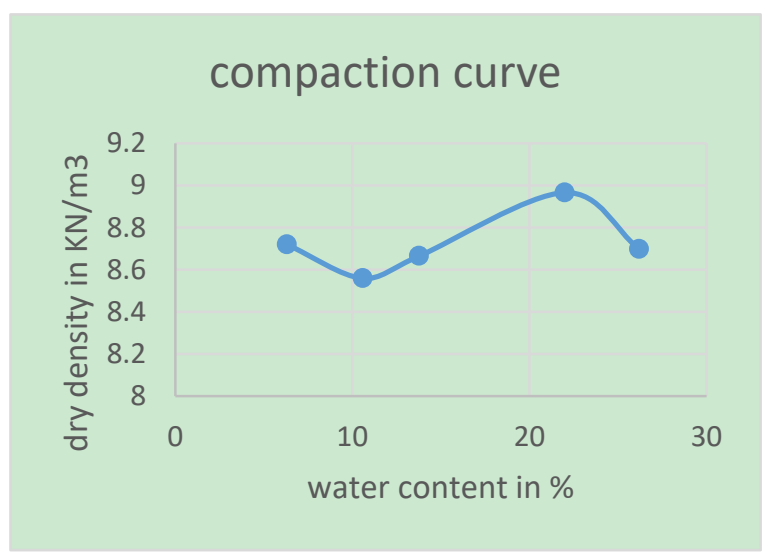

Fig. 4. Compaction curve of fly ash sample.

Also, from the graph, $\mathrm{d}_{60}, \mathrm{~d}_{10}$ and $\mathrm{d}_{30}$ sizes were determined and thus coefficient of uniformity and coefficient of curvature were calculated as 31.25 and 16.2 respectively. This suggests that fly ash is poorly graded. The compaction properties of the fly ash were determined using the Standard proctor test. A compaction curve was plotted as shown in Figure 4. From the graph, the peak of the graph gave the Maximum Dry Density (MDD) of the fly ash as $8.966 \mathrm{kN} / \mathrm{m}^{3}$ and the water content corresponding to this values gives the Optimum Moisture Content (OMC) as 21.99\%. Also, the graph on initial additions of water shows depression in the values. This could be attributed to the presence of silt particles and the behaviour is similar to the phenomenon of 'Bulking' in sands. The Liquid limit was found to be $46 \%$. The fly ash used is non-plastic as there was no water content at which the sample of fly ash could be rolled down to $3 \mathrm{~mm}$ diameter threads i.e., plasticity index was found to be zero [17]. This is due to the presence of little or no clay content in the fly ash. It has very high water holding capacity of $87.6 \%$. This indicates that fly ash contains very fine particles having greater surface area which have high water holding capacity [16].

\section{B. Rheological Properties}

The Rheograms of the prepared fly ash slurries are obtained using the Rheoplus software as shown in Fig. 5. It can be concluded that the flow behaviour of the fly ash slurry is comparable to that of a Dilatant fluid. This means that as the shear rate is increased, the viscosity of the fly ash slurry is also increased and thus showing, 'shear-thickening' behaviour. It has also been concluded that as the fly ash concentration is increased above $40 \%$, the slurry no longer behaves as a laminar fluid [18]. Thus, to increase the solid concentration, some additions need to be made as this would consume a lot of water.

Addition of bottom ash have shown better results with increasing solid concentration [9]. The use of fly ash granules, along with suitable binder, of spherical size would prove to be beneficial.
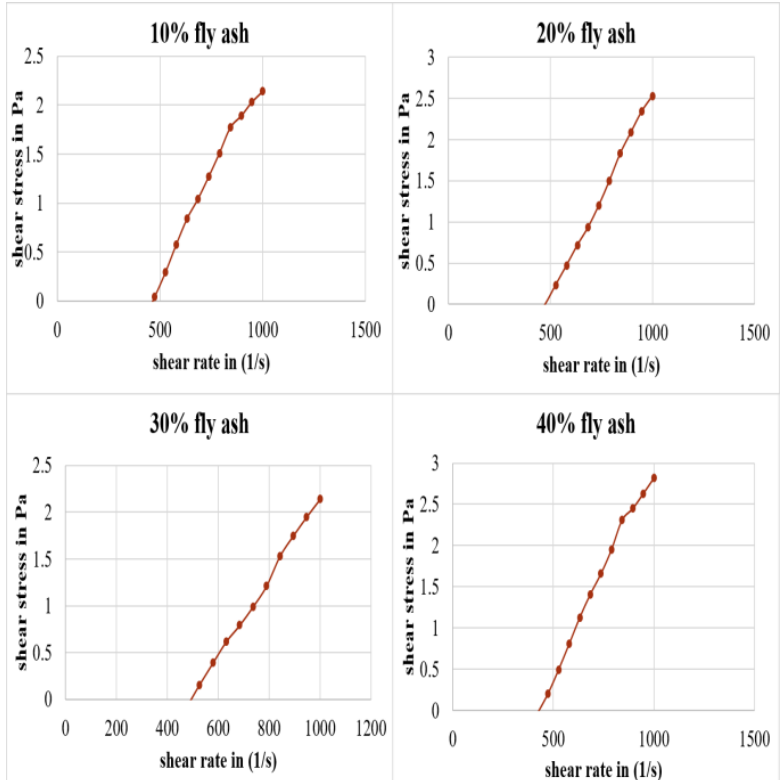

Fig. 5. Rheograms for $10 \%, 20 \%, 30 \%$, and $40 \%$ fly ash.

\section{Granulation of Fly Ash}

The granules obtained from the disc pelletizer were smooth and spherical in size. The disc speed, disc inclination and water content plays an important role in the formation of granules in the Disc Pelletizer [12]. The results of drop number and GCS at different rotation speeds and inclination are tabulated in Table III. From the table, it can be inferred that the granules prepared at $45^{\circ}$ inclination and at 45 RPM speed gave better results for drop numbers and Green Compressive Strengths. More the drop number, less vulnerable is the granule towards breakage during transportation, handling or storage. After air drying the granules, the granules become hard and show very little surface degradation. Thus, more drop number and more GCS favours its easy transportation to the back filling site without 
any potential of dust formation in the environment. Moreover, the granules formed are not of same diameter, thus, it would provide a proper packing at the fill sites. Since the granules formed are in the range of $6-12 \mathrm{~mm}$ diameter, the permeability of the packing would be increased greatly as compared to the packing of fly ash alone. Because of the smooth surface and spherical structure, the flowability of granules would increase manifolds as compared to the fly ash slurry.

TABLE III: GRANULE PARAMETERS AT DIFFERENT INCLINATION AND DIFFERENT RPM

\begin{tabular}{|c|c|c|c|}
\hline \multicolumn{4}{|l|}{$\mathbf{4 2}^{\circ}$ inclination } \\
\hline RPM & 35 & 40 & 45 \\
\hline Drop Number & 4.75 & 6.5 & 6.5 \\
\hline $\begin{array}{l}\text { Green } \\
\text { Compressive } \\
\text { Strength }\end{array}$ & 0.353 & 0.736 & 0.475 \\
\hline \multicolumn{4}{|l|}{$45^{\circ}$ inclination } \\
\hline RPM & 35 & 40 & 45 \\
\hline Drop Number & 7.0 & 4.0 & 6.5 \\
\hline $\begin{array}{l}\text { Green } \\
\text { Compressive } \\
\text { Strength } \\
\end{array}$ & 0.794 & 0.324 & 0.492 \\
\hline \multicolumn{4}{|l|}{$48^{\circ}$ inclination } \\
\hline RPM & 35 & 40 & 45 \\
\hline Drop Number & 5.0 & 4.5 & 5.5 \\
\hline $\begin{array}{l}\text { Green } \\
\text { Compressive } \\
\text { Strength }\end{array}$ & 0.376 & 0.354 & 0.421 \\
\hline
\end{tabular}

\section{CONCLUSION}

This study has focused on the potential use of industrial by-product i.e. fly ash for the purpose of mine back filling by agglomerating the fly ash fines along with lime and water. Spherical granules were obtained which would provide better packing, better compaction and reduced permeability.

1) From the study of elemental and chemical composition, it was found that the collected fly ash sample corresponds to class F fly ash as per ASTM C-618 specifications.

2) From the various physical properties such as bulk density, specific gravity, particle size analysis, Atterberg's limits, compaction, permeability, porosity and water holding capacity, it was concluded that fly ash gives better results as a stowing material [13].

3) The chemical composition of the fly ash reflected the presence of high amount of silica and oxides of Aluminium and Iron which suggests that fly ash possesses sufficient strength as a back fill material [15].

4) From the study of rheological properties, it was proved that the fly ash slurry above $40 \%$ solid concentration did not behave as a laminar fluid. The Rheograms showed that the behaviour of fly ash slurry was compared to that of a Dilatant fluid [18]. To increase the solid concentration and flowability, granulation could aid the process.
5) Since the fly ash particles were very fine, its utilisation by the process of agglomeration along with lime and water was done. Various dummy granules were prepared to find out the apt quantity of lime and water which gave sufficient strength to the granules. Lime was finalised at $30 \%$ by weight of fly ash and water at $35 \%$ by weight of fly ash taken.

6) Granules were prepared at 35, 40 and 45 RPM and also at $42^{\circ}, 45^{\circ}$ and $48^{\circ}$ inclination of the Disc pelletizer. Drop number and Green Compressive Strength were studied and it was concluded that the granules prepared at $45 \mathrm{RPM}$ and $45^{\circ}$ inclination gave the best results. After air drying, they gave better compressive strengths too.

7) The surface of the prepared granules is smooth and thus shows minimal surface degradation. Also, due to the spherical shape of the granules, the flowability of these granules would increase greatly as compared to the fly ash slurry.

It can be deduced that use of fly ash based granules as material for mine back filling process would provide bulk utilisation of the byproduct obtained from thermal power plants. Spherical granules of fly ash would ease the process of back filling and would be used at the mining sites from where coal has been extracted. This in turn could be seen as a recyclable process along with the gross utilisation of fly ash and substitution of conventional back filling materials.

\section{REFERENCES}

[1] M. K. Mishra and U. M. R. Karanam, "Geotechnical characterization of fly ash composites for backfilling mine voids," Geotech Geol Eng., vol. 24, pp. 1749-1765, 2006.

[2] A. K. Gupta and B. Paul, "Comparative analysis of different materials to be used for backfilling in underground mine voids with a particular reference to hydraulic stowing," Int J Oil, Gas Coal Technol., vol. 15, 2017.

[3] CEA. (2017). Report on fly ash generation at coal/lignite based thermal power stations and its utilization in the country for the year 2016-17. [Online]. Available: http://www.cea.nic.in/reports/others/thermal/tcd/flyash_201617.pdf

[4] A. Bijon et al., Fly Ash an Alternative for Mine Void Filling in India, vol. 5, pp. 144-148, 2016.

[5] J. Skousen et al., "Use of coal combustion by-products in mine reclamation: Review of case studies in the usa," Geosystem Eng., vol. 15, pp. 71-83, 2012.

[6] M. Ahmaruzzaman, "A review on the utilization of fly ash," Prog Energy Combust Sci., vol. 36, pp. 327-363, 2010.

[7] Z. T. Yao et al., "A comprehensive review on the applications of coal fly ash," Earth-Science Rev., vol. 141, pp. 105-121, 2015.

[8] B. K. Dutta et al., "Leaching of elements from coal fly ash: Assessment of its potential for use in filling abandoned coal mines," Fuel, vol. 88, pp. 1314-1323, 2009.

[9] R. Rani and M. K. Jain, "Effect of bottom ash at different ratios on hydraulic transportation of fl y ash during mine fi 1l," Powder Technol., vol. 315, pp. 309-317, 2017.

[10] G. Baykal and A. G. Döven, "Utilization of fly ash by pelletization process; theory, application areas and research results," Resour Conserv Recycl., vol. 30, pp. 59-77, 2000.

[11] S. P. E. Forsmo et al., "Binding mechanisms in wet iron ore green pellets with a bentonite binder," Powder Technol., vol. 169, pp. 147158, 2006.

[12] K. I. Harikrishnan and K. Ramamurthy, "Influence of pelletization process on the properties of fly ash aggregates," Waste Manag., vol. 26, pp. 846-852, 2006.

[13] D. P. Mishra and S. K. Das, "A study of physico-chemical and mineralogical properties of Talcher coal fly ash for stowing in underground coal mines," Mater Charact, vol. 61, pp. 1252-1259, 2010.

[14] A. K. Rai, B. Paul, and G. Singh, "A short note on the characterisation of fly ash from Chandrapura thermal power station, Bokaro, Jharkhand," India. J Environ Res Dev, vol. 6, pp. 139-144, 2011. 
[15] B. Kim et al., "Geotechnical properties of fly and bottom ash mixtures for use in highway embankments," J Geotech Geoenvironmental Eng, vol. 131, pp. 914-924, 2005.

[16] R. Rani and M. K. Jain, "Physiochemical and engineering characteristics of fly ash and its application in various field - A review," J Biodivers Environ Sci J Bio Env Sci., vol. 6, pp. 2220-6663, 2015.

[17] R. S. Jakka, G. V. Ramana, and M. Datta, "Shear behaviour of loose and compacted pond ash," Geotech Geol Eng., vol. 28, pp. 763-778, 2010.

[18] M. Jain, Flow Properties of Fly Ash through Viscometer with Reference to Mine Filling, 2015.

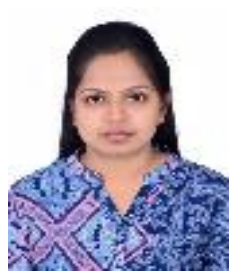

Anamika Masoom was awarded with the M.Tech in environmental science and engineering from the Department of Environmental Science and Engineering of IIT(ISM) Dhanbad in 2018 and currently working as environmental engineer at Coal India Limited.

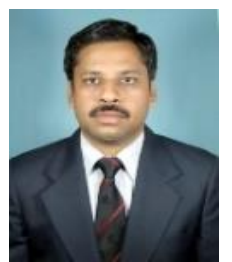

Manish Kumar Jain is associate professor, Centre of Mining Environment, Environmental Science \& Engineering Department, IIT(ISM), Dhanbad. He is a 1997 mining graduate (B.Tech, Mining Enginering) of Nagpur University. Dr. Jain was awarded with M.Tech. - Environmental Science \& Engineering in 2000 from Indian School of Mines, Dhanbad and with Ph.D. in Mining Engineering (Mine Environment) in 2004 from IIT Kharagpur. Dr Jain served Dept. of Mining Engineering, Anna University Main campus, Chennai from 2004 to 2006 and Dept. of Mining Engineering, NIT Rourkela from 2006-2007as Lecturer. Dr. Jain joined Centre of Mining Environment, ISM Dhanbad in 2007as Assistant professor. At present he is working in the same department as Associate Professor from 2010. He has authored more than 50 research papers and guided $9 \mathrm{Ph} . \mathrm{D}$. Scholar and 18 M.Tech students. Dr Jain also written one book on Fly ash.

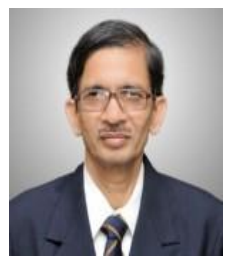

R. Venugopal is a professor at the Department of fuel and Mineral Engineering of IIT(ISM), Dhanabd. Prof. R. Venugopal served the institute for more than 35 years. Prof. R. Venugopal is a recipient of several award including National Minerals award, Ministry of Mines, Govt. Of India in 1995. Prof. R. Venugopal is author of more than 75 technical papers and book chapters. 